\title{
Publisher Correction: An automated Raman-based platform for the sorting of live cells by functional properties
}

Kang Soo Lee, Márton Palatinszky, Fátima C. Pereira (D), Jen Nguyen, Vicente I. Fernandez, Anna J. Mueller (iD, Filippo Menolascina, Holger Daims, David Berry (D), Michael Wagner (D) and Roman Stocker (D)

Correction to: Nature Microbiology https://doi.org/10.1038/s41564-019-0394-9, published online 18 March 2019.

In the 'side view' section of Fig. 1a in the version of this Article originally published, the graphical representation of the Raman laser beam was not correct; the amended Fig. 1a is shown below. In addition, an error in the layout of Fig. 2 led to the 'Labelled' and 'Unlabelled' labels being lost; the figure has now been corrected, with 'Labelled' applied to panels b-e and 'Unlabelled' to panels f-i. Finally, author M.P. was mistakenly referred to as M.C.P. in the Acknowledgements section; this has now been amended. 

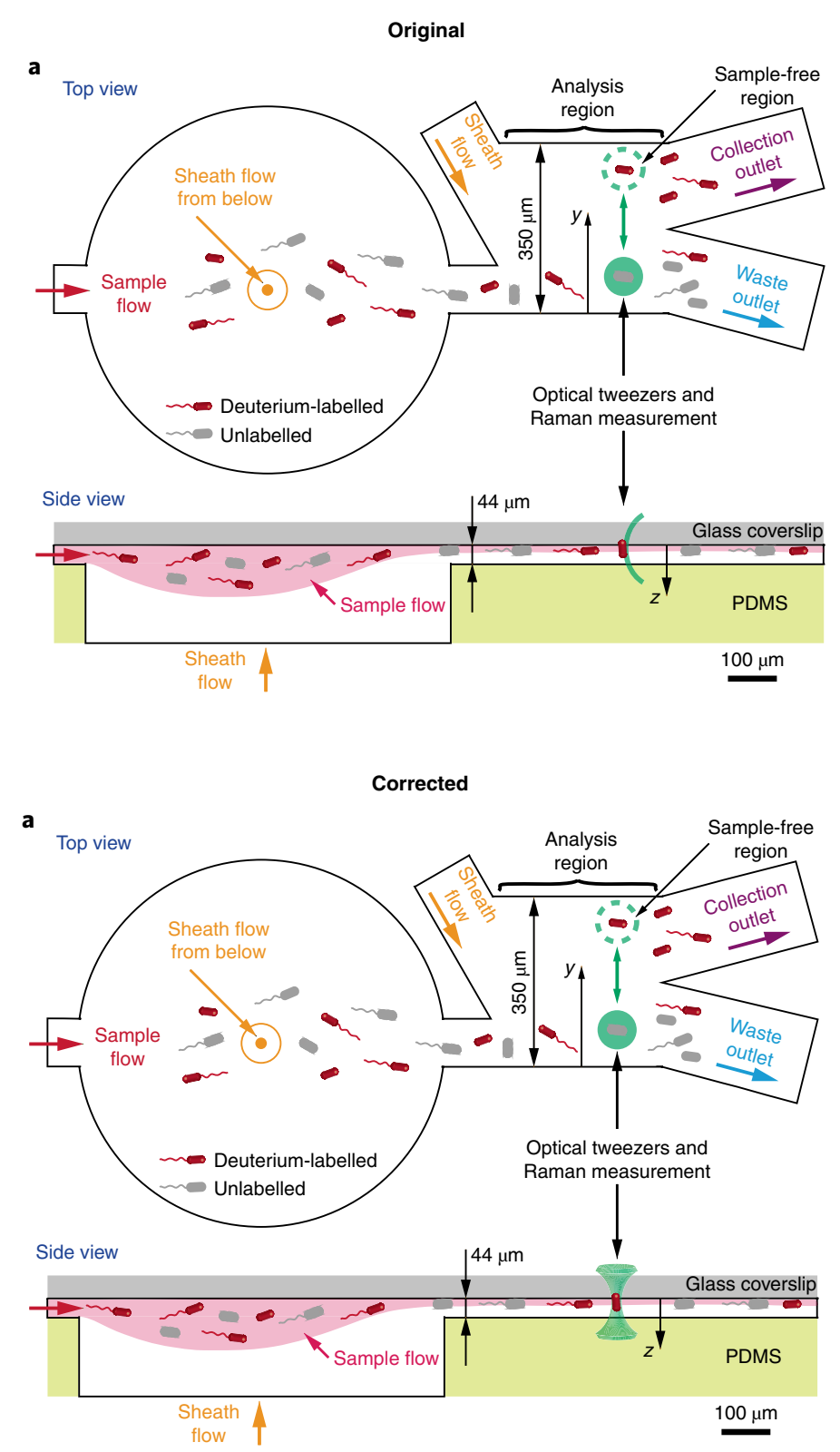

Fig. 1a | Original and corrected.

Published online: 12 April 2019

https://doi.org/10.1038/s41564-019-0446-1 